\title{
P127: Hand hygiene survey: a prospective, interventional study of current practices in a multicentre regional hospital
}

\author{
O Clerc, P Deriaz* , B Duvillard, P Vanderavero, P Erard \\ From 2nd International Conference on Prevention and Infection Control (ICPIC 2013) \\ Geneva, Switzerland. 25-28 June 2013
}

\section{Introduction}

Hand hygiene $(\mathrm{HH})$ compliance is of paramount importance to prevent infections in hospital settings.

\section{Objectives}

We started an 18 months project of monitoring and improvement of $\mathrm{HH}$ in September 2012. We aimed to modify behaviours in order to obtain a minimal compliance of $80 \%$ by the end of the project.

\section{Methods}

All professionals in direct contact with patients are planned to be evaluated during 8 rounds of observations. Compliance with the five indications of $\mathrm{HH}$ as defined by the World Health Organisation is rated by direct observation by trained personnel. Excessive indications are also quoted. An immediate feed-back is transmitted to the observed professionals. Results are provided to each unit by professional category, and units are secondarily ranked. Restitution of results occurs using a dedicated journal that is sent to all hospital collaborators. Other communication and training tools are sequentially developed. Infection control unit is available on request for training interventions in units, with priority for the ones showing the lowest compliance.

\section{Results}

Each audit evaluated around 3000 indications for $\mathrm{HH}$ in 51 units. The first round of observations showed a general compliance with $\mathrm{HH}$ indications of $61 \%$, ranging globally from $48 \%$ to $69 \%$ depending on heath-care workers categories. Extremes measured for individuals varied between 6 and 100\%. The intervention was wellaccepted in the hospital, and unsatisfying results resulted in spontaneous requests for training in 12 units ( $24 \%$ of all units). Second round of observations showed a global improvement of compliance with $\mathrm{HH}$ to $73 \%$.

\section{Conclusion}

Short term evaluation of an ongoing prospective, interventional study of hand hygiene evaluation using restitution of results as primary mean of intervention showed a significant increase in the compliance with $\mathrm{HH}$ in a multicentre, regional hospital. Persistence of this improvement and active participation of caregivers as a marker of greater awareness to $\mathrm{HH}$ will be prospectively monitored.

\section{Disclosure of interest}

None declared.

Published: 20 June 2013

doi:10.1186/2047-2994-2-S1-P127

Cite this article as: Clerc et al:: P127: Hand hygiene survey: a prospective, interventional study of current practices in a multicentre regional hospital. Antimicrobial Resistance and Infection Control 2013 2(Suppl 1):P127.

Hôpital Neuchâtelois, Site de Pourtalès, 2000 Neuchâtel, Switzerland

(c) 2013 Clerc et al; licensee BioMed Central Ltd. This is an Open Access article distributed under the terms of the Creative Commons 